DOI: 10.25557/0031-2991.2020.01.54-59

(с) Коллектив авторов, 2020

УДК 616-092

Калиш С.В. ${ }^{1}$, Лямина С.В. ${ }^{1}$, Кузнецова Л.В. ${ }^{1}$, Буданова О.П. ${ }^{2}$, Малышева Е.В. ${ }^{\text {, }}$ Говоров А.В. ${ }^{1}$, Прилепская Е.А.' ${ }^{1}$ Пушкарь Д.Ю.', Малышев И.Ю., ${ }^{1,2}$

\title{
М3 макрофаги останавливают деление клеток предстательной железы больного раком простаты
}

\author{
1 ФГБОУ ВО «Московский государственный медико-стоматологический университет имени А.И. Евдокимова» Минздрава России, \\ 127473, г. Москва, Россия, Делегатская ул., д. 20, стр. 1; \\ 2 ФГБНУ «Научно-исследовательский институт общей патологии и патофизиологии», \\ 125315, г. Москва, Россия, ул. Балтийская, д. 8
}

В развитии рака предстательной железы (РПЖ) макрофаги играют важную роль. Многие опухоли выделяют противовоспалительные цитокины, которые перепрограммируют М1 фенотип макрофагов на проопухолевый М2 фенотип. М2 макрофаги подавляют противоопухолевый иммунитет, способствуют делению и метастазированию опухолевых клеток. Предыдущие исследования позволили нам обосновать предположение, что деление опухолевых клеток РПж человека может быть ограничено особым М3 фенотипом макрофагов. Фенотип М3, в отличие от М1 фенотипа, реагирует на противовоспалительные цитокины увеличением продукции провоспалительных противоопухолевых цитокинов, что способствует сохранению их противоопухолевых свойств в зоне опухоли. Цель исследования - проверка гипотезы о способности МЗ макрофагов останавливать деление клеток предстательной железы больного РПЖ. Методика. В работе использовали макрофаги мышей, выделенные из перитонеального лаважа и макрофаги человека, полученные из моноцитов крови больных РПЖ. Фенотип М3 макрофагов получали добавлением в среду культивирования IFN-ү, ингибиторов STAT3, STAT6 и SMAD3 с последующей стимуляцией липополисахаридом. Результаты. Показано, что МЗ макрофаги мышей и человека ограничивали деление клеток предстательной железы больных РПЖ в условиях 2D (на плоскости) культивирования на 43\% и 93\%, соответственно. При 3D (в объеме) культивировании М3 макрофаги мышей не ограничивали, а М3 макрофаги человека лишь незначительно ограничивали деление клеток предстательной железы у больных РПж. Заключение. Результаты работы делают обоснованными дальнейшие исследования и разработку клинической версии биотехнологии лечения рака предстательной железы с использованием МЗ макрофагов.

Ключевые слова: макрофаги; рак предстательной железы; перепрограммирование макрофагов.

Для цитирования: Калиш С.В., Лямина С.В., Кузнецова Л.В., Буданова О.П., Малышева Е.В., Говоров А.В., Прилепская Е.А., Пушкарь Д.Ю., Малышев И.Ю. МЗ макрофаги останавливают деление клеток предстательной железы больного раком простаты. Патологическая физиология и экспериментальная терапия. 2020; 64(1): 54-59.

DOI: 10.25557/0031-2991.2020.01.54-59

Для корреспонденции: Малышев Игорь Юрьевич, е-mail: iymalyshev1@gmail.com
Финансирование. Исследование проводилось при финансовой поддержке Министерства здравоохранения Российской
Федерации (Государственное задание №056-00149-18-00 от 26 декабря 2017)
Конфликт интересов. Авторы заявляют об отсутствии конфликта интересов.
Поступила 25.10 .2019
Принята к печати 16.01 .2020
Опубликована 25.02.2020

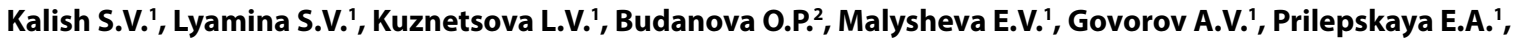
Pushkar D.Yu. ${ }^{1}$, Malyshev I.Yu. ${ }^{1,2}$

\section{M3 macrophages stop division of prostate cell from a patient with prostate cancer}

\author{
'A.I. Evdokimov Moscow State University of Medicine and Dentistry, \\ Delegatskaya Str., 20/1, Moscow 127473, Russia; \\ ${ }^{2}$ Institute of General Pathology and Pathophysiology, \\ Baltijskaya Str. 8, Moscow 125315, Russia
}

Macrophages play an important role in the development of prostate cancer (PCa). Many tumors, including PCa, secrete anti-inflammatory cytokines that reprogram the M1 macrophage phenotype into the pro-tumor M2 phenotype. M2 macrophages suppress antitumor immunity and promote division and metastasis of tumor cells. We hypothesized that the division of human PCa cells may be restricted by a specific M3 macrophage phenotype. The M3 phenotype, in contrast to the M1 phenotype, responds to antiinflammatory cytokines by increasing the production of inflammatory anti-tumor cytokines and retains its anti-tumor properties 
in the tumor area. The aim of the study was to test the hypothesis on the ability of M3 macrophages to stop division of prostate cells from patients with PCa. Methods. This study used murine macrophages isolated from the peritoneal lavage and human macrophages obtained from blood monocytes of patients with PCa. The M3 macrophage phenotype was obtained by adding IFN- $\gamma$, STAT3, STAT6, and SMAD3 inhibitors to the cultural medium followed by lipopolysaccharide (LPS) stimulation. Results. Murine and human M3 macrophages restricted the division of patients' PCa cells in the conditions of 2D cultivation by $43 \%$ and $93 \%$, respectively. In 3D cultivation, murine M3 macrophages did not restrict whereas human M3 macrophages only slightly limited the division of prostate cells from PCa patients. The results of the study warrant further research and development of a clinical biotechnology for PCa treatment with reprogrammed M3 macrophages.

Keywords: macrophages; prostate cancer; macrophage reprogramming.

For citation: Kalish S.V., Lyamina S.V., Kuznetsova L.V., Budanova O.P., Malysheva E.V., Govorov A.V., Prilepskaya E.A., Pushkar D.Yu., Malyshev I.Yu. M3 macrophages stop division of prostate cell from a patient with prostate cancer. Patologicheskaya Fiziologiya i Eksperimental naya terapiya. (Pathological Physiology and Experimental Therapy, Russian Journal). 2020; 64(1): 54-59. (in Russian).

DOI: 10.25557/0031-2991.2020.01.54-59

\begin{abstract}
For correspondence: Igor Yu. Malyshev, Doctor of Medical Sciences, Head of the Department of Pathological Physiology oh the Moscow State University of Medicine and Dentistry n.a. A.I. Evdokimov; 20, str. 1, ul. Delegatskaya, Moscow, 127473, Russia, Head of stress and adaptation laboratory of the Institute of General Pathology and Pathophysiology; 8, ul. Baltiyskaya, Moscow, 125315, Russian Federation, e-mail: iymalyshev1@gmail.com
\end{abstract}

Information about authors:

Budanova O.P.; https://orcid.org/0000-0002-6650-5082

Acknowledgements. The study was supported by the Ministry of Health of the Russian Federation (State-sponsored Task \# 056- 0014918-00 of December 26, 2017)

Conflict of interest. The authors declare no conflict of interest.

Received 25.10.2019

Accepted 16.01.2020

Published 25.02.2020

Предстательная железа (ПЖ) - железисто-мышечный орган, который окружает дистальную часть мочеиспускательного канала у мужчин. ПЖ вырабатывает секрет, который стимулирует подвижность сперматозоидов и препятствует попаданию микробов в верхние мочевые пути. ПЖ не является жизненно важным органом, однако появление опухоли в нем может привести к летальному исходу. В России за последние 10 лет число мужчин с выявленным раком железы (РПЖ) возросло в 4 раза [1], а 5-летняя выживаемость больных с метастатическим РПЖ не превышает 30\%. Поэтому разработка новых видов терапии остается актуальной задачей.

В развитии РПЖ важную роль играют макрофаги [2-6]. М1 макрофаги участвует в уничтожении опухоли благодаря продукции оксида азота [7] и провоспалительных цитокинов [8], активации природных киллеров [9] и антиген-презентации [10]. Опухоль выделяя противовоспалительные IL-10, TGF- $\beta$ и IL-13 [11, 12], репрограммируют M1 фенотип макрофагов в проопухолевый М2 фенотип [13]. М2 макрофаги продуцируют много антивоспалительных цитокинов, факторов роста и протеиназ и поэтому подавляют иммунитет, способствуют пролиферации и метастазированию опухолевых клеток $[13,14]$. Ранее нами показано, что особый М3 фенотип $[15,16]$ реагирует на противовос- палительные цитокины продукцией провоспалительных цитокинов и существенно ограничивает рост мышиной карциномы Эрлиха [17]. Цель работы - проверка гипотезы о способности М3 макрофагов останавливать деление клеток РПЖ человека.

\section{Методика}

Исследование выполнено в соответствии с этическими нормами и международными правилами работы с биоматериалом человека.

Все процедуры, связанные с содержанием и использованием животных, проводили с соблюдением директив Европарламента и Совета европейского союза (2010/63/EU), регламентирующих использование животных в научных целях. Протокол экспериментов был утвержден Комитетом по этике ФГБНУ НИИОПП. Мыши C57BL/6J были получены из вивария «Андреевка» (Москва, Россия, http://andreevka.msk.ru) и содержались в соответствии с правилами ВО3 (www.cioms.ch/publications/guidelines).

Реактивы. Ингибитор Stat3 (S3I204, Axon Med, США), ингибитор Stat6 (As1517499, Axon Med, США), IFN- $\gamma$ (Invitogen, CШA), LPS (Sigma-Aldrich, CШA), ингибитор SMAD3 (SIS3, Calbiochem, США), Fetal Bovine Serum (FBS) (Thermo Hyclone, UK), DMEM/F12 (Панэко). 
Выделение макрофагов мышей. Макрофаги мышей выделяли из перитонеального лаважа по методу $\mathrm{X}$. Zhang и соавт. [18]. Затем макрофаги помещали в культуральные планшеты со средой RPMI-1640 с 10\% FBS, 100 ед/мл пенициллина и 100 мкг/мл стрептомицина (PS) при $37^{\circ} \mathrm{C}$ и $5 \% \mathrm{CO} 2$.

Получение макрофагов человека. Макрофаги получали из моноцитов крови больных РПЖ. К 10 мл крови добавляли 40 мкл гепарина в течение 15 мин центрифугировали при 3000 об/мин. Полученную лейкоцитарную бляшку отделяли, смешивали с 10 мл лизис-буфера $(0.825$ г NH4Cl, 0.0037 г ЭДТА в 100 мл воды), размешивали и центрифугировали 4 мин при 1000 об/мин. Супернатант выливали и повторяли процедуру еще 2 раза. Затем осадок ресуспендировали в 1 мл RPMI-1640 и доводили концентрацию клеток до $1 \times 10^{6}$ в мл. Клетки рассаживали в лунки планшета и инкубировали 1 ч в $\mathrm{CO}_{2}$ инкубаторе. После этого среду вместе с всплывшими клетками удаляли, а к оставшимся на дне клеткам добавляли среду RPMI-1640 с FBS и PS. Через 7 сут клетки приобретали фенотип макрофагов [19].

Выделение клеток из фрагмента ткани ПЖ больных РПЖ. Фрагмент ткани ПЖ размером $1.5 \times 1.0$ см получали после робот-ассистированной радикальной простатэктомии у пациентов с морфологически верифицированным РПЖ. Использовали фрагменты ткани ПЖ больных с аденокарциномой 7 (4+3) баллов по шкале градации Глисона (прогностическая группа 3 ). Фрагмент разрезали на кусочки по 1-3 $\mathrm{mm}^{3}$ и инкубировали 12 ч в растворе коллагеназы 2 типа с $10 \mu \mathrm{M}$ ингибитора протеинкиназ Y-27632. Затем кусочки ткани промывали в 10 мл DMEM/F12 и центрифугировали при $200 \mathrm{~g} 5$ мин. Осадок ресуспендировали в 1 мл TrypLE c $10 \mu \mathrm{M}$ Y-27632 и инкубировали 15 мин. Затем диссоциированные клетки промывали в DMEM/F12 центрифугированием при $200 \mathrm{~g} 5$ мин [20].

Репрограммирование М3 фенотипа макрофагов. Для получения М3 фенотипа [17], в среду DMEM/F12, добавляли 20 нг/мл IFN- $\gamma, 5$ мкг/мл ингибитора STAT3, 10 мкг/мл ингибитора STAT6 и 2 нмоль/мл ингибитоpa SMAD3 и культивировали 12 ч. Затем макрофаги стимулировали 500 нг/мл липополисахарида (ЛПС) 24 ч. Контрольные М0 макрофаги культивировали 36 ч в среде DMEM/F12, содержащей $10 \%$ FBS.

Оценка влияния М3 макрофагов мыши и человека на деление клеток ПЖ больных РПЖ в условиях 2D культивирования. В лунки плашки к 500 тыс. макрофагов мыши через 12 ч после репрограммирования вместе с ЛПС вносили 25 тыс. клеток ПЖ больного РПЖ. В другие лунки к 20 тыс. макрофагов людей через 12 ч после ре- программирования вместе с ЛПС вносили 1 тыс. клеток ПЖ больного РПЖ. Через 24 ч культивирования подсчитывали количество клеток ПЖ, культивируемых с М0 и М3 макрофагами. Макрофаги отделяли по методике, описанной ранее [14].

Оценка влияния МЗ макрофагов мыши и человека на деление клеток ПЖ больных РПЖ в условиях 3D культивирования. Поскольку 2D культивирование не воспроизводит особенности объемного роста опухоли, нами также было оценено влияние М3 макрофагов на деление клеток ПЖ больного РПЖ в 3D условиях. Для формирования сфероидов (3D) в лунки низкоадгезивного 96 луночного планшета с DMEM/F12, 10\% FBS и PS вносили по 500 клеток ПЖ больного РПЖ. За 24-48 ч формирования сфероида количество клеток в нем увеличивалось до 3,5-4 тыс. К сфероиду добавляли макрофаги в отношении 10 к 1 клетке сфероида. Через 24 часа сфероид пипетировали и подсчитывали количество клеток в сфероиде, культивированном с М3 и с М0 макрофагами. Таким образом, оценивали эффект макрофагов. Схема экспериментов представлена на рис. 1.

Статистический анализ проводили с использованием t-критерия Стьюдента. Данные представлены в виде среднего (М) со стандартными ошибками среднего ( \pm SEM). Различия считались статистически значимыми при $p<0,05$. Все эксперименты проведены в 3 повторах.

\section{Результаты}

1. М3 макрофаги мышей и человека ограничивали деление клеток ПЖ больных РПЖ в условиях 2D культивирования. При 2D культивировании за 24 ч количество клеток ПЖ больных РПЖ увеличилось с 25000 до $56000 \pm 1000$. Добавление мышиных М0 макрофагов увеличивало их число на 25\%, а добавление мышиных M3 макрофагов статистически значимо замедляло деление клеток ПЖ больных РПЖ на 43\% ( $p<0.05)$. Добавление М0 макрофагов человека увеличивало на $56 \%$, а добавление М3 макрофагов человека замедляло на 93\% деление клеток ПЖ больных РПЖ $(p<0.01)$.

Таким образом, и мышиные и человеческие М3 макрофаги замедляли деление клеток ПЖ больных РПЖ при 2D культивировании. Эффект человеческих M3 макрофагов был существенно более выраженным. Увеличение деления клеток ПЖ больных РПЖ при добавлении М0 макрофагов согласуется с клиническими наблюдениями, что увеличение числа макрофагов в опухоли ухудшает прогноз заболевания [21].

2. М3 макрофаги мышей не влияли, а МЗ макрофаги человека незначительно ограничивали деление клеток ПЖ больных РПЖ в условиях $3 D$ культивирования. После 
DOI: 10.25557/0031-2991.2020.01.54-59

24-часового культивирования сфероида без макрофагов количество клеток в нем увеличилось с $3700 \pm 300$ до 7000£820. Культивирование сфероида с М0 макрофагами как мыши, так и человека, увеличило количество новых клеток в сфероиде на 33\%. Добавление мышиных М3 макрофагов к сфероиду не влияло на деление клеток ПЖ больных РПЖ в сфероиде, а добавление человеческих М3 макрофагов на $33 \%$ снижало количество появившихся в результате деления клеток в сфероиде ( $p>0.05)$. Выявленный эффект проявлялся в виде тенденции.

\section{Обсуждение}

Противоопухолевую активность макрофагов пытались повышать путем стимуляции Toll-подобных рецепторов [22]; культивированием в без-FBS среде [23]; повышения активности генов IFN- $\gamma$ и IL-12 [24] или блокированием про-опухолевых рецепторов на макрофагах [25, 26]. Однако, опухоль перепрограммировала макрофаги в проопухолевый М2 фенотип [13] и сводила на «нет» противоопухолевый эффект макрофагов. Качественное отличие М3 фенотипа от макрофагов других фенотипов, состоит в том, что М3 макрофаги переключают сигналы проопухолевой среды на выработку противоопухолевых цитокинов. Повидимому, эта особенность лежит в основе противоопухолевого эффекта М3 макрофагов, продемонстрированного в нашем исследовании.

Мы обнаружили, что М3 макрофаги мышей сушественно меньше, по сравнению с М3 макрофагами человека подавляют деление клеток ПЖ больных РПЖ. Тем не менее, сам, факт, что М3 макрофаги мышей на $43 \%$ подавляют деление клеток ПЖ больного РПЖ, свидетельствует о возможной перспективности ксено-

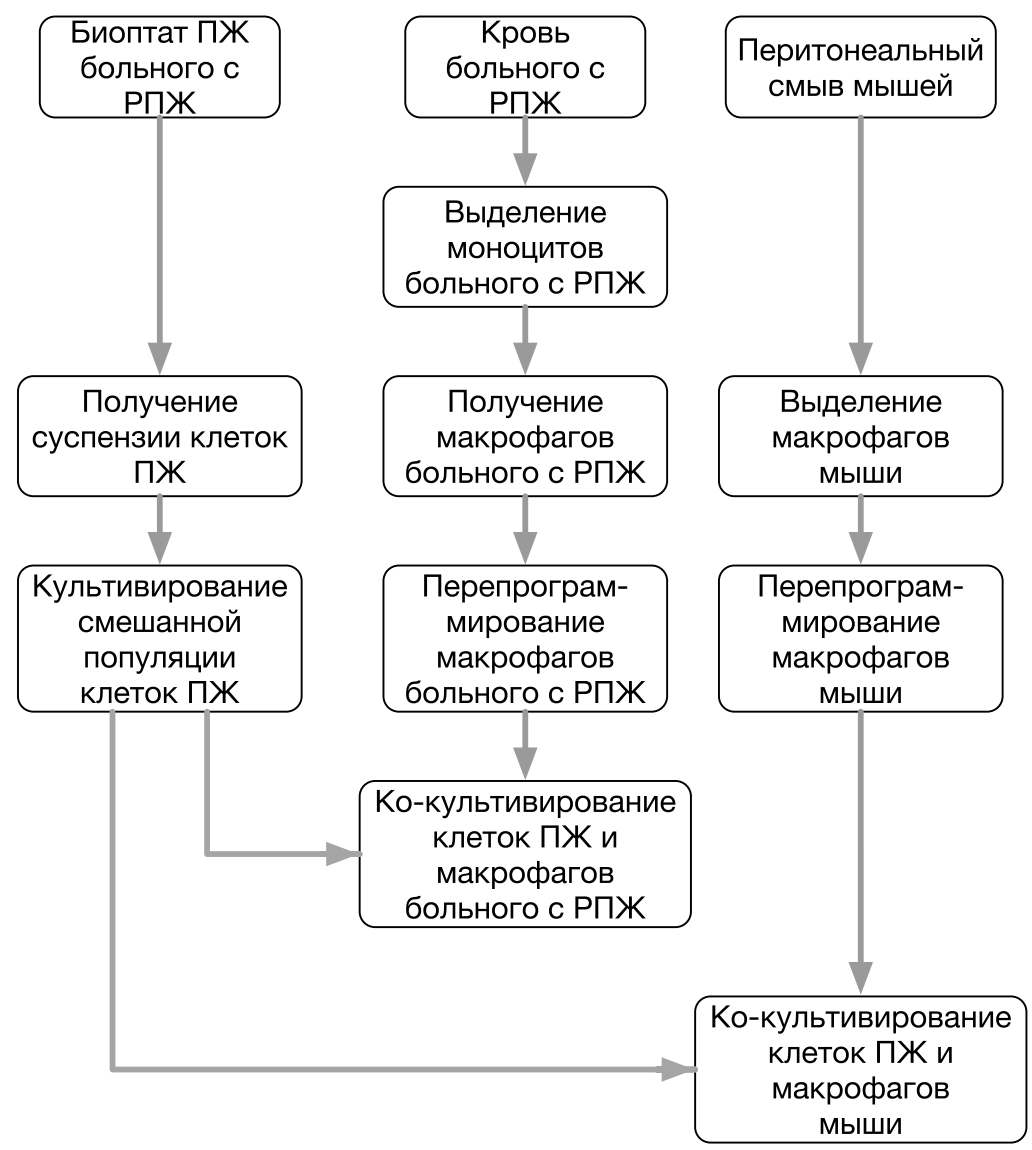

Рис. 1. Графическая схема эксперимента. 
генной клеточной иммунотерапии рака после удаления видовых антигенов.

В условиях 3D культивирования антиопухолевый эффект М3 макрофагов человека был выражен меньше, по сравнению с эффектом при 2D культивировании. Вероятно, это связано с тем, что при 2D кокультивировании существенно больше М3 макрофагов взаимодействуют с клетками ПЖ больного РПЖ, чем при 3D культивировании, когда значительная часть клеток ПЖ находится внутри сфероида и недоступна для макрофагов. Это указывает на то, что для повышения эффективности М3 макрофагов в терапии солидных опухолей следует увеличивать проницаемость этих опухолей для М3 макрофагов.

Интерпретация наших результатов ограничивается отсутствием данных о фенотипе исследуемых клеток ПЖ. Эксперименты для определения соотношения эпителиальных и стромальных клеток, эпителия секреторного и базального, доброкачественных и злокачественных клеток, наличия и уровня андрогеновой чувствительности будут рассматриваться в дальнейших исследованиях.

Несмотря на оставшиеся вопросы и необходимость дальнейших исследований, сам факт, что М3 макрофаги подавляют рост клеток ПЖ больных РПЖ, делает обоснованным разработку клинической версии биотехнологии для лечения РПЖ с использованием М3 макрофагов.

\section{Участие авторов:}

Концепция и дизайн исследования - Малышев И.Ю, Малышева Е.В.

Сбор и обработка материала - Калиш С.В., Лямина С.В., Кузнецова Л.В., Буданова О.П

Статистическая обработка - Калиш С.В., Лямина С.В., Кузнецова Л.В.

Написание текста -Калиш С.В., Лямина С.В., Кузнецова Л.В., Буданова О.П.

Редактирование текста -Говоров А.В., Прилепская Е.А., Пушкарь Д.Ю.

\section{Литература \\ (п.п. 2-16; 18-26 см. References)}

1. Пушкарь Д.Ю., Говоров А.В., Сидоренков А.В., Прилепская Е.А., Ковылина М.В. Ранняя диагностика рака предстательной железы. Методические рекомендации № 19. М.; 2015.

17. Раецкая А.А., Калиш С.В., Лямина С.В., Малышева Е.В., Буданова О.П., Бахтина Л.Ю. и др. Репрограммированные in vitro на м3 фенотип макрофаги останавливают рост солидной карциномы in vivo. Патологическая физиология и экспериментальная терапия. 2018; 62(1):41-6. DOI: https://doi.org/10.25557/ 0031-2991.2018.01.41-46.

\section{References}

1. Pushkar' DY, Govorov AV, Sidorenkov AV, Prilepskaya EA, Kovylina MV. Early diagnosis of prostate cancer. Methodical recommendations No. 19. [Rannyaya diagnostika raka predstatel'noy zhelezy. Metodicheskie rekomendatsii № 19]. Moscow, 2015. (in Russian)

2. Condeelis J, Pollard JW. Macrophages: obligate partners for tumor cell migration, invasion, and metastasis. Cell. 2006; 124(2): 263-6. DOI: 10.1016/j.cell.2006.01.007.

3. Sica A, Schioppa T, Mantovani A, Allavena P. Tumor-associated macrophages are a distinct M2 polarized population promoting tumor progression: potential targets of anti-cancer therapy. Eur J Cancer. 2006; 42:717-727. https://doi.org/10.1016/j.ejca.2006.01.003.

4. Mills CD, Thomas AC, Lenz LL, Munder M. Macrophage: SHIP of Immunity. Front Immunol. 2014; 5: 620. DOI: https://doi. org/10.3389/fimmu.2014.00620.

5. Mills CD, Kincaid K, Alt JM, Heilman MJ, Hill AM. M-1/M-2 macrophages and the Th1/Th2 paradigm. J Immunol. 2000; 164(12): 6166-73. DOI: https://doi.org/10.4049/jimmunol.164.12.6166.

6. Mantovani A, Sozzani S, Locati M, Allavena P, Sica A. Macrophage polarization: tumor-associated macrophages as a paradigm for polarized M2 mononuclear phagocytes. Trends Immunol. 2002; 23: 54955. DOI: https://doi.org/10.1016/S1471-4906(02)02302-5.

7. Zeini M, Través PG, López-Fontal R, Pantoja C, Matheu A, Serrano $\mathrm{M}$ et al. Specific contribution of p19 (ARF) to nitric oxide-dependent apoptosis. J Immunol. 2006; 177: 3327-36. DOI: https://doi. org/10.4049/jimmunol.177.5.3327.

8. Tsung K, Dolan JP, Tsung YL, Norton JA. Macrophages as effector cells in interleukin 12-induced $\mathrm{T}$ cell-dependent tumor rejection. Cancer Res. 2002; 62: 5069-75.

9. Sharma M. Chemokines and receptors: orchestrating a fine balance between health and disease. Critical Reviews in Biotechnology. 2009; 30: 1-22. DOI:https://doi.org/10.3109/07388550903187418.

10. Dunn GP, Old LJ, Schreiber RD. The immunobiology of cancer immunosurveillance and immunoediting. Immunity. 2004; 21: 137-48. DOI: https://doi.org/10.1016/j.immuni.2004.07.017.

11. Khong HT, Restifo NP. Natural selection of tumor variants in the generation of "tumor escape" phenotypes. Nat Immunol. 2002;3:9991005

12. Zou W. Regulatory T cells, tumor immunity and immunotherapy. Nat Rev Immunol. 2006; 6: 295-307.

13. Stout RD, Watkins SK and Suttles J. Functional plasticity of macrophages: in situ reprogramming of tumor-associated macrophages. J Leukoc Biol. 2009; 86(5): 1105-9. DOI: https://doi.org/10.1189/ jlb.0209073/

14. Kalish SV, Lyamina SV, Manukhina EB, Larionov NP, Malyshev IYu. Macrophages reprogrammed in vitro towards the M1 phenotype and activated with LPS extend lifespan of mice with carcinoma. Med Sci Monit Basic Res. 2015; 21: 226-34. DOI: 10.12659 / MSMBR.895563.

15. Malyshev I, Manukhina EB and Malyshev Y. Physiological organization of immune response based on the homeostatic mechanism of matrix reprogramming. Med Hypotheses. 2014; 82(6): 754-65. DOI:https://doi.org/10.1016/j.mehy.2014.03.019.

16. Malyshev I and Malyshev Yu. Current concept and update of the macrophage plasticity concept: intracellular mechanisms of reprogramming and M3 macrophage "switch" phenotype. Biomed Res Int. 2015; 2015: 341308. DOI: http://dx.doi.org/10.1155/2015/341308.

17. Raetskaya A.A., Kalish S.V., Lyamina S.V., Malysheva E.V., Budanova O.P., Bakhtina L.Yu., Malyshev I.Yu. Reprogrammed in vitro 
for the $\mathrm{m} 3$ phenotype, macrophages stop the growth of solid carcinoma in vivo. Patologicheskaya fiziologiya i eksperimental'naya terapiya. 2018; 62(1): 41-6. (in Russian). DOI: https://doi. org/10.25557/0031-2991.2018.01.41-46.

18. Zhang X, Goncalves R, Mosser DM. The isolation and characterization of murine macrophages. Curr Protoc Immunol. 2008; Chapter 14: Unit 14.1. DOI: 10.1002/0471142735.im1401s83.

19. Menck, K., Behme, D., Pantke, M., Reiling, N., Binder, C., Pukrop, T., Klemm, F. Isolation of Human Monocytes by Double Gradient Centrifugation and Their Differentiation to Macrophages in Tefloncoated Cell Culture Bags. J. Vis. Exp. 2014, (91), e51554, doi: $10.3791 / 51554$.

20. Toivanen, R., Taylor, R.A., Pook, D.W., Ellem, S.J. \& Risbridger, G.P. Breaking through a roadblock in prostate cancer research: an update on human model systems. J. Steroid Biochem. Mol. Biol. 2012; 131: 122-31. DOI: https://doi.org/10.1016/j.jsbmb.2012.01.005

21. Tsutsui S, Yasuda K, Suzuki K, Tahara K, Era S. Macrophage infiltration and its prognostic implications in breast cancer: the relationship with VEGF expression and microvessel density. Oncol Rep. 2005; 14(2): 425-31. DOI: https://doi.org/10.3892/or.14.2.425.
22. Ramanathan S, Jagannathan N. Tumor associated macrophage: the phenotypes, traits and functions. Iran J Cancer Prev. 2014; 7(1): 1-8.

23. Rey-Giraud F, Hafner M, Ries $\mathrm{CH}$. In vitro generation of monocyte-derived macrophages under serum-free conditions improves their tumor promoting functions. PLoS One. 2012; 7(8): e42656. DOI:https://doi.org/10.1371/journal.pone.0042656.

24. Satoh T, Saika T, Macrophages transduced with an adenoviral vector expressing IL-12 suppress tumor growth and metastasis in a preclinical metastatic prostate cancer model. Cancer Res. 2003;63(22):7853-7860.

25. Peng J, Tsang JY, Li D, et al. Inhibition of TGF- $\beta$ signaling in combination with TLR7 ligation re-programs a tumoricidal phenotype in tumor-associated macrophages. Cancer Lett. 2013; 331(2): 239-49 . DOI: https://doi.org/10.1016/j.canlet. 2013.01.001.

26. Baay M, Brouwer A, Pauwels P, Peeters M, Lardon F. Tumor cells and tumor-associated macrophages: secreted proteins as potential targets for therapy. Clin Dev Immun. 2011; 2011: 565187. DOI: $10.1155 / 2011 / 56587$

\section{Сведения об авторах:}

Калии Сергей Валерьевич, ст. лаб. каф. патофизиологии ФГБОУ ВО «МГМСУ им. А.И. Евдокимова» Минздрава России, e-mail: anahoretes@mail.ru;

Лямина Светлана Владимировна, доктор мед. наук, проф. каф. патофизиологии ФГБОУ ВО «МГМСУ им. А.И. Евдокимова» Минздрава России, e-mail: svlvs@mail.ru;

Кузнецова Лариса Вячеславовна, канд. биол. наук, вед. науч. сотр. лаб. клеточных биотехнологий ФГБОУ ВО «МГМСУ им. А.И. Евдокимова» Минздрава России, е-mail: lorakuznetsova@gmail.com;

Буданова Ольга Петровна, ст. науч. сотр., ФГБНУ НИИОПП, e-mail: opbudanova@yandex.ru;

Малышева Елена Васильевна, доктор мед. наук, проф. каф. патофизиологии ФГБОУ ВО «МГМСУ им. А.И. Евдокимова» Минздрава России, e-mail: elenamalysheva@hotmail.com;

Говоров Александр Викторович, доктор мед. наук, проф. каф. урологии ФГБОУ ВО «МГМСУ им. А.И. Евдокимова» Минздрава Россиию, e-mail: dr.govorov@gmail.com;

Прилепская Елена Анатольевна, доктор мед. наук, проф. каф. урологии ФГБОУ ВО «МГМСУ им. А.И. Евдокимова» Минздрава России, е-mail: prilepskayae@mail.ru;

Пушкарь Дмитрий Юрьевич, чЛ.-корр. РАН, доктор мед. наук, проф. зав. каф. урологии ФГБОУ ВО «МГМСУ им. А.И. Евдокимова» Минздрава России, e-mail: Pushkardm@mail.ru;

Малышев Игорь Юрьевич, доктор мед. наук, проф., зав. каф. патологической физиологии ФГБОУ ВО «МГМСУ им. А.И. Евдокимова» Минздрава России и зав. лаб. стресса и адаптации, ФГБНУ НИИОПП, e-mail: iymalyshev1@gmail.com 